\title{
Un sujet historiographique et ses dimensions idéologiques : le territoire de la Moldavie et la frontière du sud du Royaume Galicie-Volhynie selon les historiens et les archéologues soviétiques moldaves
}

\section{Iurie Stamati}

\begin{abstract}
The purpose of this study is to highlight the ideological dimensions of the Soviet Moldavian historiographical discourse concerning the question whether the territory of Moldavia belonged to the medieval Kingdom of Galicia-Volhynia or not. We have shown that, between the late 1930s and the early 1950s, this discourse was deeply marked by the Stalinist resuscitation of pan-Russian and pan-Slavic ideology, by the Soviet-Romanian dispute over Bessarabia, as well as by the campaign of inoculating the people of this province and of RASSM with the sense of belonging to the Eastern Slavic world and, therefore, to the USSR. At the time, in addition to the argument asserting that the territory of Moldavia had formerly belonged to the Galicia-Volhynia, the medieval Moldavian state was estimated to have partially owned its existence to this very kingdom. We have also noted the case of a Russian historian who, at that time, expressed his skepticism regarding the theory according to which the territory of Moldavia had belonged to the Kingdom of Galicia-Volhynia. We have explained this situation by highlighting the fact that the ideological control maintained by the Soviet State over its historiography was never complete: thus, some potentially unwanted publications were allowed to be released. Since the late 1950s, in a more permissive ideological context, other authors (archaeologists) have been sharing this skepticism.
\end{abstract}

Keywords: Galicia-Volhynia, historical Moldova, MSSR, soviet archaeology, soviet historiography, pan-Russian ideology, pan-Slavic ideology.

Depuis le milieu de $\mathrm{XIX}^{\mathrm{e}}$ siècle, la question de la frontière de sud de la GalicieVolhynie occupe une place très importante dans les discours nationalistes ruthéno-ukrainien et roumain. Àl'époque, les Ruthènes, qui à côté des Roumains constituaient les principales ethnies de la Bucovine autrichienne (territoire qui avant 1775 a fait partie de la principauté de Moldavie), commencent à revendiquer leurs droits sur la partie de cette province où ils étaient majoritaires. Leur but était la création d'une province nationale ruthène. ${ }^{1}$ Dans ce contexte, l'important

1 I. Nistor, Românii și rutenii în Bucovina, studiu istoric și statistic (Bucureşti: Librăriile SOCEC \& Comp. şi SFETEA), 1915, 1, 145-167. Selon certains auteurs, la question de la frontière de sud 
historien ruthène du XIX ${ }^{\mathrm{e}}$ siècle, Isidor” Šaranevič”2 estima qu'aux XIII ${ }^{\mathrm{e}}$ et XIV ${ }^{\mathrm{e}}$ siècles, la Bucovine de même que le reste de la Moldavie historique faisaient partie de la Galicie-Volhynie. En suivant Jan Długosz, un lettré polonais du XV ${ }^{e}$ siècle, Šaranevič" nota que les Roumains, à leur arrivée, au XIV e siècle, sur le territoire de la future Moldavie, y ont trouvé les Ruthènes. Ils se seraient installés parmi ces derniers « comme des visiteurs et pour ne pas éveiller leur soupçon ont assumé leurs coutumes et leurs croyances, mais avec le temps, en devenant très nombreux, ils les ont bannis et ont créé un pays séparé, la Moldavie ».

La réponse roumaine a été sur mesure. Les Ruthènes, selon l'historien Dimitrie Onciul, ${ }^{3}$ « n'ont pas eu la chance de créer en Moldavie un ordre politique. Après les dominations barbares qui se sont succédé durant plus d'un millénaire, un autre peuple a été appelé à accomplir cette œuvre civilisatrice: les Roumains. Ils sont les premiers, après leurs ancêtres les Romains, à donner à ce pays une importance historique par la fondation de l'État moldave, l'ayant arraché des mains d'une barbarie ancestrale au profit de la civilisation. »

Cette bataille historiographique va se poursuivre au-delà du XIX ${ }^{\mathrm{e}}$ siècle. ${ }^{4}$ La question de l'appartenance du territoire de la Moldavie au royaume GalicieVolhynie va attirer aussi l'attention de l'historiographie soviétique moldave. Souvent, les opinions formulées par ses représentants n'étaient pas non plus dépourvues d'une finalité politique ou idéologique, ce que nous allons tenter de démontrer dans la présente étude. ${ }^{5}$

\section{L'aube d'un nouveau sujet d'étude}

C'est surtout depuis la fin des années 1930 que la Galicie-Volhynie commence à attirer le regard des historiens soviétiques - fait explicable par la nécessité de justifier l'annexion de 1939 du territoire polonais à l'URSS, ${ }^{6}$ mais aussi par l'ambiance idéologique générale du pays marquée par l'abandon par Staline du

de la Galicie-Volhynie surgit pour la première fois vers le milieu des années 1770, étant liée à la justification de l'annexion de l'extrémité nord de la principauté moldave, appelée désormais la Bucovine, par l'Empire romain germanique. Cf. Ș. Purici, „Cu privire la concepția istorică despre dominația Haliciului asupra teritoriului din nordul Moldovei în sec. XII-XIV." Revista de istorie a Moldovei 4, 1992, 3.

2 Isidor" Šaranevič”, Istorija Galicko-Volodimirskoi Rusi ot" najdavnjšix" vremen" do roku 1453 (L'vov: Institut Stavropirijskogo, 1863), 184-185.

3 Dmitrie Onciul, Originile Principatelor Române (Bucureşti: Stab. de Arte Grafice « Elzevir », 1899), 84.

4 Nistor, Românii şi rutenii în Bucovina.

5 La cible de cette étude n'est donc pas d'établir la pertinence d'un tel ou tel avis sur cette question.

6 A.V. Majorov, Galicko-Volynskaja Rus'. Očerki social'no-političeskix otnošenij v domongol'skij period. Knjaz', bojare i gorodskaja obščina (Sankt-Peterburg: Universitetskaja kniga, 2001), 70. 
discours cosmopolite en faveur du patriotisme soviétique fondé sur une base culturelle pan-russe et pan-slaviste. ${ }^{7}$

Dans l'historiographie soviétique des années 1940-1950, cet État médiéval slave apparu vers la fin du XII ${ }^{e}$ siècle par la jonction des principautés ruthènes de Galicie et de Volhynie était traité comme partie intégrante des « terres russes », comme celui qui après l'affaiblissement de la Russie kiévienne ${ }^{8}$ aurait pris la relève, en devenant le centre économique et politique le plus proéminent de peuple russe. Selon les auteurs soviétiques ${ }^{9}$, c'est grâce à l'effort de ses « knyaz talentueux $\gg$ que la frontière russe de l'ouest a été longtemps protégée contre les envahisseurs hongrois, lituaniens et surtout polonais.

\section{La place de la Galicie-Volhynie dans l'histoire de la Moldavie selon Vasilij Senkevič et Naum Narcov}

L'inoculation à la population de la République autonome soviétique socialiste moldave (la RASSM) et de la Bessarabie, encore roumaine, du sentiment d'appartenance au monde slave de l'Est et, donc, à l'URSS (campagne due au changement idéologique noté ci-dessus), ainsi que la nécessité d’argumenter les prétentions soviétiques concernant la Bessarabie ont fait en sorte que depuis la fin des années 1930 les propagandistes et les historiens moldaves tournèrent aussi leurs regards vers la Galicie-Volhynie. En 1939, le propagandiste Vasilij Senkevič ${ }^{10}$ qui venait de recevoir son diplôme en histoire ${ }^{11}$ n'avait pas encore décidé si jadis la Bessarabie fit partie de ce royaume. Mais, l'année suivante, son collègue Naum

7 C'est l'impossibilité de réaliser le rêve d'une révolution mondiale et la menace du nazisme qui ont amené l'Union soviétique à transformer son visage, d'un pays ouvert, exportateur de la révolution prolétarienne en une « cité assiégée ». C’est ainsi que le pouvoir central s'est tourné vers un discours patriotique soviétique. Selon les suggestions de l'historien américain Terry Martin, le coloriage de ce discours en nuances russophiles constitua, entre autres, une sorte de remerciement à la nation soviétique à laquelle Staline croyait pouvoir se fier le plus, à la nation soviétique qu'il voyait comme la plus progressiste et la plus révolutionnaire de toutes les autres nations soviétiques. Cf. Terry Martin, The Affirmative Action Empire: Nations and Nationalism in the Soviet Union, 1923-1939 (Ithaca-Londres: Cornell University Press, 2001), 394-431.

8 La Russie kiévienne a eu aussi sa place d'honneur dans la propagande soviétique. Ce que nous allons révéler dans un article que nous comptons publier en 2014.

9 N.S. Deržavin, «Proisxoždenie moldavskogo naroda. » Sovetskaja nauka 12, 1940, 22-23; V. Pičeta, Osnovnye momenty istoričeskogo razvitija Zapadnoj Ukrainy i Zapadnoj Belorusii (Moskva: Gosudarstvennoe social'no-èkonomičeskoe izdatel'stvo, 1940), 6, 16; K.G. Guslistyj, « Obrazovanie ukrainskoj narodnosti », Istorija Ukrainskoj SSSR, édité par A.K. Kosimenko, tom I, (Kiev: Naukova dumka, 1953), 101-102.

${ }^{10}$ Vasilij Senkevič, « Istoričeskie puti razvitija Sovetskoj Moldavii », Moldova Sovetike (Tiraspol': Editura de Stat a Moldovei, 1939), 25.

${ }^{11}$ K. Zubku, « Senkevič Vasilij Markovič », Moldavskaja sovetskaja ènciklopediya, édité par I.K. Vartičan, v. VI, (Kišinev: Glavnaja redakcija MSĖ, 1976), 112. 
Narcov, ${ }^{12}$ le plus important historien de la RASSM de l'époque, ${ }^{13}$ tranchera sans équivoque : «Pendant le morcellement féodal » la Bessarabie a bel et bien fait partie de ce royaume. Selon Narcov, la Galicie-Volhynie aurait eu une grande influence politique et culturelle sur cette province. ${ }^{14}$

Après la guerre dans un contexte idéologique encore monopolisé par un discours pan-russe et pan-slaviste extrême, Vasilij Senkevič revient sur ce sujet et affirme que la Galicie-Volhynie, à côté de la Russie kiévienne, a même joué un rôle très important dans l'apparition de l'État médiéval moldave. C'est à l'intérieur de la Galicie-Volhynie et de la Russie kiévienne, affirme-t-il, ${ }^{15}$ que les ancêtres des Moldaves « en développant les forces des productions et les relations de classes sociales ont mis les bases de leur État indépendant ». Dans la première synthèse d'histoire de la République soviétique socialiste moldave (la RSSM), parue en 1951, ses auteurs, parmi lesquels Senkevič s'y trouve, ${ }^{16}$ voyaient la GalicieVolhynie comme un «État d'avant-garde » qui a occupé « une place d'honneur sur la carte politique d'Europe ». Cet État aurait laissé « un riche et précieux héritage matériel et spirituel » au peuple moldave.

Il faut toutefois préciser que ni à cette époque ni après, l'appartenance du territoire de la Moldavie à la Galicie-Volhynie n'a constitué le sujet d'aucune étude minutieuse de la part des historiens et des archéologues moldaves. Leurs avis sont exposés, sans qu'ils se fassent trop de souci pour les argumenter, dans le contexte de l'exploration des sujets comme l'ethnogenèse des Moldaves et l'apparition de

${ }^{12}$ N. Narcov, « Istoričeskie sud'by Bessarabii i Moldavii (kratkij očerk) », Istorik-marksist 9/85, 1940, 86-87.

${ }^{13}$ N.P. Smochină, „Institutul de cercetări ştiinţifice din Republica Moldovenească”, Însemnări ieşene V/3, 1938, 517-519; N.P. Smochină, Republica Moldovenească a Sovietelor (Bucureşti: Cartea Românească, 1938), 23; Wilhelmus Petrus van Meurs, Chestiunea Basarabiei în istoriografia comunistă, traduit par Ion Stanciu, (Chişinău: Arc, 1996), 192.

${ }^{14}$ Cette campagne idéologique ne s'arrêtera pas là. L'ultimatum soviétique adressé à l'État roumain stipulait que l'ethnie majoritaire de la Bessarabie est ukrainienne, c'est pourquoi Narcov et d'autres historiens soviétiques vont se dépêcher de déclarer la population roumanophone de cette province comme étant presque ukrainienne. Cf. Narcov, Istoričeskie sud'by Bessarabii i Moldavii, 89-90; N.S. Deržavin, « Proisxoždenie moldavskogo naroda », Sovetskaja nauka 12, 1940, 27.

${ }^{15}$ V.M. Senkevič, « Obrazovanie moldavskogo gosudarstva », Učenye zapiski I, 1949, 80.

${ }^{16}$ F.A. Grekul, V.M. Senkevič, « Karpato-Dnestrovskie zemli v sostave Kievskogo gosudarstva i Galicko-Volynskogo knjažestva », Istorija Moldavii (ot drevnejšix vremen do Velikoj oktjabr'skoj socialističeskoj revoljucii), édité par A.D. Udal'cov, tom I, (Kišinev: Škoala sovietikè, 1951), 70; F.A. Grekul, V.M. Senkevič, « Obrazovanie Moldavskogo gosudarstva i formirovanie moldavskoj narodnosti », Istorija Moldavii (ot drevnejšix vremen do Velikoj oktjabr'skoj socialističeskoj revoljucii), édité par A.D. Udal'cov, tom I, (Kišinev: Škoala sovietikè, 1951), 92-94. 
leur État médiéval, ${ }^{17}$ l’amitié historique moldavo-russo-ukrainienne ${ }^{18}$ ou de la problématique de l'archéologie slavo-russe. ${ }^{19}$

\section{La frontière du sud de la Galicie-Volhynie selon l'historien russe Arsenij Nasonov}

Selon une tradition préexistante dans l'historiographie tsariste, ${ }^{20}$ pour appuyer l'idée de l'appartenance de la région de Moldavie à la Galicie-Volhynie, le plus souvent les auteurs impliqués invoquaient le poème épique Dit de l'Ost d'Igor. ${ }^{21}$

${ }^{17}$ N.S. Deržavin, « Proisxoždenie moldavskogo naroda », Sovetskaja nauka 12, 1940, 43-51; V.M. Senkevič, « Obrazovanie moldavskogo gosudarstva. » Učenye zapiski I, 1949, 71-89; F.A. Grekul, V.M. Senkevič, « Karpato-Dnestrovskie zemli v sostave Kievskogo gosudarstva i Galicko-Volynskogo knjažestva », Istorija Moldavii (ot drevnejšix vremen do Velikoj oktjabr'skoj socialističeskoj revoljucii), édité par A.D. Udal'cov, tom I, (Kišinev: Škoala sovietikè, 1951), 82-97; N.A. Mohov, Formirovanija moldavskogo naroda i obrazovanie Moldavskogo gosudarstva (Kišinev: Kartja moldoveniask, 1959); N.A. Mohov, Očerki istorii formirovanija moldavskogo naroda (Kišinev: Kartja moldoveniaskè, 1978).

${ }^{18}$ N.A. Mohov, Očerki istorii moldavsko-russko-ukrainskix svjazei (s drevneišix vremen do načala XIX veka) (Kišinev: Štiinca, 1961).

${ }^{19}$ G.B. Fedorov, «Slavjane Podnestrov'ja », Po sledam drevnix kul'tur: Drevnjaja Rus', édité par G.B. Fedorov, (Moskva: Gosudarstvennoe izdatel'stvo kul'turno-prosvetitel'noj literatury, 1953), 121-154; G.B. Fedorov, Drevnie slavjane v Prutsko-Dnestrovskom meždureč’e (Moskva: Nauka, 1966); G.B. Fedorov, G.F. Čebotarenko, Pamjatniki drevnix slavjan (VI-XIII vv.), édite par P.P. Byrnja, N.A. Ketraru, (Kišinev: Štiinca, 1974).

${ }^{20}$ A. Zaščuk", Bessarabskaja oblast': Materialy dlja geografii i statistiki Rosii (Sanktpeterburg, 1862), 5.

${ }^{21}$ Depuis même avant sa première publication, en 1800 , et jusqu'à nos jours la question de l'authenticité de ce poème ne cesse pas à intriguer les divers auteurs qu'ils soient russes ou non russes. Certains l'ont considéré comme un chef-d'œuvre du XII siècle, d'autres, plus sceptiques, l'ont daté au $\mathrm{XIV}^{\mathrm{e}}, \mathrm{XV}^{\mathrm{e}}$ ou XVI ${ }^{\mathrm{e}}$ siècles. D'autres encore l'ont traité comme un faux créé au XVII ${ }^{\mathrm{e}}$ ou même au XVIII ${ }^{\mathrm{e}}$ siècle. Cf. Jean-Pierre Arrignon, La Russie médiévale (Paris: Les Belles Lettres, 2003), 156; Aleksandr Bobrov, „Problema podlinnosti « Slovo o polku Igoreve » i Efrosin Belozerskij" Acta Slavica Iaponica 22, 2005, 238-297; A.A. Zimin, Slovo o polku Igoreve (S.-Peterburg: Dmitrij Bulanin, 2006); A.A. Zaliznyak, Slovo o polku Igoreve: vzgljad lingvista (Moskva: Rukopisnye pamjatniki Drevnej Rusi, 2008). Pour l'historiographie officielle soviétique le Dit de l'Ost d'Igor était la matérialisation du génie littéraire russe de l'époque médiévale. Le XII siècle était considéré comme le moment indubitable de sa création. Ce n'est quau début des années 1960 que l'historien moscovite Aleksandr Zimin a osé de douter d'une telle datation en proposant le XVIII ${ }^{e}$ siècle comme date de sa rédaction. Certains de ceux qui ont connu à l'époque son opinion y ont adhéré. Pourtant la section idéologique du Comité central de Parti communiste et la direction de l'Academie des Sciences de l'URSS ont fait de leur mieux pour discréditer cette tendance. Longtemps, le texte intégral de l'analyse faite par Zimin sur le Dit de l'Ost d'Igor n'a pas été accessible qu'à un public restreint. Son ouvrage sur ce poème, sur lequel il a continué à travailler jusqu'à sa mort survenue en 1980, a été publié en 2006. Cf. A.A. Zimin, Slovo o polku Igoreve (S.-Peterburg: Dmitrij Bulanin, 2006); Pour l'histoire de l'analyse de Zimin 
Selon celui-ci, le prince galicien-volhynien Iaroslav de Galitch (env. 1130-1187) aurait exercé son pouvoir jusqu'au Danube. ${ }^{22}$ Ce poème est pourtant contredit par la chronique Galicienne-volhynienne rédigée au cours du XIII ${ }^{e}$ siècle. Selon celle-ci, les frontières du sud du royaume Galicie-Volhynie ne dépasseraient pas les cours supérieures du Dniestr et du Prut. ${ }^{23}$ C'est justement cette idée qui était suggérée au début des années 1950 par l'historien russe Arsenij Nasonov ${ }^{24}$ qui admettait toutefois, dans l'un de ses livres parus à Moscou, que les knyaz galiciens-volhyniens ont pu exercer un certain contrôle du territoire moldave, un contrôle qui serait néanmoins superficiel et éphémère. ${ }^{25}$

voir Formozov, 1992. A.A. Zimin, Slovo o polku Igoreve, Voprosy istorii 6-7: 96-103; Echo.msk. ru 2006. "Ne tak: Rukopisi ne gorjat: k vyxodu knigi Aleksandra Zimina, « Slovo o polku Igoreve »." Consulté novembre 2013. http://echo.msk.ru/programs/netak/45301/; Zimina, V.G. 2006. „K čitatelju.” In Slovo o polku Igoreve, par A.A. Zimin, 3-4 (S.-Peterburg: Dmitrij Bulanin, p. 3-4); Tvorogov, O.V. „O knige A.A. Zimina”. In Slovo o polku Igoreve, par A.A. Zimin, 5-7. S.Peterburg: Dmitrij Bulanin, 2006, p. 5-7; L.N. Puškarev, "A.A. Zimin. «Slovo o polku Igoreve». CPb.2006.516 s." Voprosy istorii 11, 2007, 163-166; L.V. Sokolova, "Novye mify o starom (po povodu interv'ju na radiostanciyax «Exo Moskvy » $\mathrm{i}$ «Svoboda » v svyazi s vyxodom knigi A.A. Zimina «Slovo o polku Igoreve », Studia Slavica et Balcanica Petropolitana 1/2, 2007, 23 38; L.V. Sokolova, éd. Istorija spora o podlinnosti „Slova o polku Igoreve”: materialy diskusii 1960-x godov (Sankt-Peterburg: Puškinskij dom, 2010).

${ }^{22}$ Christiane Pighetti, trad. La Geste du Prince Igor (Paris: Minos/La Différence, 2005), 51-52.

${ }^{23}$ Certaines études plus récentes démontrent qu'à part la chronique Galicienne-volhynienne d'autres sources médiévales contredisent les témoignages de Dit de l'Ost d'Igor. Cf. Roman Rabinovič, « Problema prisustvija Galickoj Rusi v Karpato-Dnestrovskix zemljakh v 1140-1240 gg. » Rusin: meždunarodnyj istoričeskij žurnal 2 (2), 2005. 69-85. Cela ne signifie pas bien sûr qu'il faut écarter complètement la possibilité que certaines régions de la partie nord de la Moldavie historique qui se trouvaient dans le voisinage immédiat de la frontière galicienne-volhynienne consignée par la chronique citée ci-dessus aient pu se trouver à un moment donné sous l'influence ou le contrôle intrinsèque des rois galicien-volhyniens. Par contre, établir avec exactitude une ligne frontalière galicienne-volhynienne ne sera jamais possible tout d'abord parce que les frontières médiévales ne constituaient pas des lignes simples et immuables comme celles des États modernes. Cf. Lucien Febvre, Pour une histoire à part entière (Paris: Éditions de l'École des hautes études en sciences sociales, 1962), 11-24; Wolfgang Kaiser, « Penser la frontière - notions et approches », Histoire des Alpes/Storia delle Alpi/Geschichte des Alpen 3, 1998, 63-74.

${ }^{24}$ A.N. Nasonov, «Russkaja zemlja » $i$ obrazovanie territorii drevnerusskogo gosudarstva, istorikogeografičeskoe issledovanie (Moskva: Izdatel'stvo Akademii nauk SSSR, 1951), 137-144.

${ }^{25}$ Dans son ouvrage Nasonov cite le Dit de l'Ost d'Igor pour illustrer l'intérêt des knyazs galiciens-volhyniens pour la région du Danube inférieur. Cf. A.N. Nasonov, « Russkaja zemlja » i obrazovanie territorii drevnerusskogo gosudarstva, istoriko-geografičeskoe issledovanie (Moskva: Izdatel'stvo Akademii nauk SSSR, 1951), 142. Pourtant, nous ne savons pas si à cette époque Nasonov avait réellement confiance en cette source. Ce qui est certain c'est qu'au début des années 1960, après avoir lu l'ouvrage d'Aleksandr Zimin, il a manifesté ouvertement son scepticisme concernant son authenticité. Cf. L.N. Puškarev, "A.A. Zimin. «Slovo o polku Igoreve ». CPb.2006.516 s." Voprosy istorii 11, 2007, 164. 
En dépit de la centralisation proverbiale de l'URSS et bien que les maitres du Parti aimaient croire qu'ils avaient le contrôle total de l'historiographie, cela n'a pas été tout à fait le cas. C'est sans doute de cette façon qu'il faut comprendre la parution de livre de Nasonov qui, comme nous avons pu le constater, exposait une opinion différente de celle propagée à la même époque par l'historiographie soviétique moldave. D’ailleurs, selon l'archéologue et anthropologue russe Lev Klejn, ${ }^{26}$ souvent dans une république ou un centre de recherche soviétique la publication d'un ouvrage pouvait être refusé parce qu'il n'était pas trouvé conforme du point de vu idéologique, mais il pouvait être trouvé même très conforme et publié sans aucune entrave dans une autre république ou un autre centre de recherche. Klejn ${ }^{27}$ est tenté justement d'expliquer ce phénomène par le fait que le contrôle idéologique du champ historiographique soviétique, même dans la période stalinienne, n’a pas été total. Selon Klejn, la concurrence entre les chercheurs ou les diverses institutions académiques, la bureaucratisation excessive de la censure et le manque de vigilance ou même de compétence de la part des censeurs ont joué en faveur de la publication d'un article ou d'un livre potentiellement indésirable.

\section{La frontière du sud de la Galicie-Volhynie selon l'archéologue ukrainien Boris Timoščuk}

Jusquà la fin de l'époque soviétique, dans toutes les synthèses historiques de l'Ukraine soviétique qui constituaient une sorte de cartes de visite de l'historiographie officielle de cette république, ses auteurs propagèrent l'idée selon laquelle le territoire de la Moldavie historique fit partie de la GalicieVolhynie. ${ }^{28}$ Toutefois, vers la fin des années 1960, probablement à cause d'une ambiance politique plus relâchée ressentie au niveau de toute l'historiographie

${ }^{26}$ Lev Klejn, Fenomen sovetskoj arkheologii (Sankt-Peterburg: FARN, 1993), 85-86.

${ }^{27}$ Ibidem, 81-89.

${ }^{28}$ K.G. Guslistyj, « Obrazovanie ukrainskoj narodnosti » , Istorija Ukrainskoj SSSR, édité par A.K. Kosimenko, tom I, (Kiev: Naukova dumka, 1953), 98; K.G. Guslistyj, « Obrazovanie ukrainskoj narodnosti », Istorija Ukrainskoj SSSR, édité par A.K. Kosimenko, tom I, (Kiev: Naukova dumka, 1956), 99; K.G. Guslistyj, « Obrazovanie ukrainskoj narodnosti », Istorija Ukrainskoj SSSR, édité par K.K. Dubina, tom I, (Kiev: Naukova dumka, 1969), 92. Comme nous le montrerons plus loin, au début des années 1980, quoique la position de l'historiographie ukrainienne officielle sera plus nuancée, elle resta essentiellement la même. Cela contredit l'avis de l'archéologue et historien médiéviste moldave Anatolie Gorodenco, selon lequel, « dans la délimitation de la frontière de Galicie [-Volhynie] l'historiographie soviétique n’a jamais passé la frontière de la République socialiste roumaine ». Cf. Anatolij Gorodenko, « Galicko-vološskie svjazi v XIII-XIV vekax (Kontekst formirovanija Moldavskogo knjažestva) ». Rusin: meždunarodnyj istoričeskij žurnal 2 (2), 2005, 86. 
soviétique après la mort de Staline, ${ }^{29}$ l'archéologue ukrainien Boris Timoščuk se laissa aussi séduit par les données de la chronique Galicienne-volhynienne, surtout que le résultat de ses recherches semblait les confirmer. Timoščuk remarqua que certains artefacts datés de $\mathrm{XI}^{\mathrm{e}}$ au $\mathrm{XIV}^{\mathrm{e}}$ siècle et qu'il voyait comme une marque archéologique de la Galicie-Volhynie n'étaient pas présents sur le territoire de la Moldavie soviétique. En plus, sur les cours supérieurs du Dniestr et du Prut, donc sur le territoire ukrainien, il identifia et étudia plusieurs citadelles qu'il interpréta comme des forteresses frontalières. ${ }^{30}$

\section{La Galicie-Volhynie et le territoire de la Moldavie selon l'archéologie moldave}

Le sujet de l'appartenance du territoire moldave à la Galicie-Volhynie n'a pas réussi à attirer l'attention de l'archéologue moscovite Georgij Fedorov, le créateur de la première génération d'archéologues médiévistes moldaves. ${ }^{31}$ Quelques notes glissées dans certains de ses ouvrages c'est tout ce qu'il a consacré à ce sujet. Selon ces notes, ${ }^{32}$ au début des années 1950 il était convaincu qu'au XII ${ }^{\text {- }}$ XIII ${ }^{\mathrm{e}}$ siècles, « une grande partie de la Moldavie », il ne précise pas laquelle, fit partie de cet État slave. Cependant, depuis la fin des années 1950, probablement à cause de la même ambiance politique plus permissive, mais aussi grâce à un certain recul du discours russophile, Fedorov n'afficha plus autant de certitude. Dans ses articles, ${ }^{33}$ il suggère uniquement la présence d'une certaine influence

${ }^{29}$ L.A. Sidorova, Ottepel' v istoričeskoj nauke, sovetskaja istoriografija pervogo poslestalinskogo desjatiletija (Moskva: Pamjatniki istoričeskoj mysli, 1997); L.A. Sidorova, « Ottepel' v istoričeskoj nauke, seredina 50-x - seredina 60-x gg. », Istoriceskaja nauka Rossii v XX veke, édité par A.N. Sakharov et L.A. Sidorova, (Moskva: Skriptorij, 1997), 243-268.

${ }^{30}$ B.O. Timoščuk, Pivnična Bukovina - zemlya slovjans'ka (Užgorod: Karpati, 1969), 66; B.O. Timoščuk, Davn'orus'ka Bukovina (X - perša polovina XIV st.) (Kiiv: Naukova Dumka, 1982), 68-86.

${ }^{31}$ Georgij Fedorov arrive en RSSM en 1951 dans le but de chercher les traces archéologiques des Ouliches et Tivertes, peuplades mentionnées par la Chronique des années écoulées. Il va coopter plusieurs étudiants provenant des universités moldaves. Certains d'entre eux, comme Gheorghij Cebotarenco, Pavel Bârnia, Ion Hâncu, Lazar' Polevoi et Isak Rafalovič vont poursuivre une carrière archéologique en constituant la première génération d'archéologues médiévistes moldaves. Cf. Mark Tkačuk, « Georgij Borisovič Fedorov (1917-1992) », Stratum plus 5, 1999, 7-13.

${ }^{32}$ G.B. Fedorov, « Slavjanskie gorodišča v Moldavii (k itogam rabot Moldavskoj arxeologičeskoj èkspedicii v 1952 godu). » Vestnik Akademii nauk SSSR 4, 1953, 50; G.B. Fedorov, « Slavjane Podnestrov'ja », Po sledam drevnix kul'tur: Drevnjaja Rus', édité par G.B. Fedorov, (Moskva: Gosudarstvennoe izdatel'stvo kul'turno-prosvetitel'noj literatury, 1953), 152.

${ }^{33}$ G.B. Fedorov, « Rezultatele şi problemele principale ale cercetărilor arheologice din sud-estul U.R.S.S., referitoare la primul mileniu al e.n. », Studii şi cercetări de istorie veche 10/2, 1959, 403; G.B. Fedorov, « Raboty Prutsko-Dnestrovskoj ekspedicii v 1959 godu. » Kratkie soobščenija Ins- 
politique de la part de la Galicie-Volhynie sur l'extrémité nord de la Moldavie. Dans la première moitié des années 1970, il sera plus explicite. Étant influencé par les études de l'archéologue ukrainien - cité d'ailleurs dans ses ouvrages - il va affirmer sans aucune équivoque et à l'unisson avec son ex-étudiant moldave, Gheorghij Cebotarenco, ${ }^{34}$ que le territoire de RSSM ne fit jamais partie de cet État. $^{35}$

Pourtant, Fedorov ${ }^{36}$ soutiendra que le territoire de RSSM a servi de lieu de refuge pour une population originaire de la Galicie-Volhynie, les soi-disant «Vygontsy galiciens ». Selon lui, ${ }^{37}$ ils étaient très nombreux et ils disposaient même d'une «grande et terrible armée ». Leur présence en Moldavie serait prouvée par la découverte d'une «céramique spécifique galicienne», «bien qu'en petite quantité $\gg$, comme Fedorov $^{38}$ le reconnaissait lui-même. ${ }^{39}$ Selon les données dont nous disposons, tous ses ex-étudiants suivront son exemple et au moins dans leurs publications, ils ne parleront pas de l'appartenance du territoire de leur république à la Galicie-Volhynie.

tituta arxeologii 86, 1961, 79; G.B. Fedorov, « Itogi i zadači izučenija drevneslavjanskoj kul'tury Iugo-Zapada SSSR », Kratkie soobščenija Instituta arxeologii 105, 1965, 29; G.B. Fedorov, Drevnie slavjane v Prutsko-Dnestrovskom meždureč’e (Moskva: Nauka, 1966), 22.

${ }^{34}$ G.B. Fedorov, G.F. Čebotarenko, Pamjatniki drevnix slavjan (VI-XIII vv.), Édité par P.P. Byrnja, N.A. Ketrar, (Kišinev: Štiinca, 1974), 9-10.

${ }^{35}$ Il sera intéressant de voir si en plus d'ouvrage de Boris Timoščuk c'est aussi l'analyse de Zimin sur le Dit de l'Ost d'Igor qui a contribué à la radicalisation de l'opinion de Fedorov. Nous avons noté que le texte de cette analyse n'a été accessible qu'à un public restreint. Or, l'ex-professeur de Fedorov, Artemij Arcixovskij, et son ancien ami, l'archéologue Aleksandr Mongajt en faisait partie. Cf. L.V. Sokolova, éd. Istorija spora o podlinnosti „Slova o polku Igoreve”: materialy diskusii 1960-x godov (Sankt-Peterburg: Puškinskij dom, 2010). Ce dernier inclina même à donner du crédit à cette analyse et plaida pour sa publication, car selon lui, elle pouvait contribuer à empêcher «l'instauration du dogmatisme dans la science $\gg$. Ibidem, 486.

${ }^{36}$ G.B. Fedorov, « Itogi i zadači izučenija drevneslavjanskoj kul’tury Iugo-Zapada SSSR », Kratkie soobščenija Instituta arxeologii 105, 1965, 29-30; G.B. Fedorov, Drevnie slavjane v Prutsko-Dnestrovskom meždureče (Moskva: Nauka, 1966), 22-23.

${ }^{37}$ Ibidem, 22.

${ }^{38}$ G.B. Fedorov, G.F. Čebotarenko, Pamjatniki drevnix slavjan (VI-XIII vv.), Édité par P.P. Byrnja, N.A. Ketraru, (Kišinev: Štiinca, 1974), 9-10.

${ }^{39}$ Les sources ne donnent aucune information sur l'endroit où ces « Vygontsy galiciens » habitaient. Elles suggèrent uniquement que pour rejoindre la coalition antimongole, à l'occasion de la fameuse bataille de Kalka, ils auraient commencé leur chemin en descendant sur le Dniestr. Cf. Nikolaj Tel'nov et Vjačeslav Stepanov, Nikolaj Russev, Roman Rabinovič, «I... razošlis' slavjane po zemle ». Iz istorii Karpato-Dnestrovskix zemel' VI-XIII vv. (Kišinev: Vysšaja antropologičeskaja škola, 2002), 203-204. 


\section{Le point de vue de Nikolaj Moxov}

Le propagandiste et historien Senkevič mourut en 1954. Vers la fin des années 1950, Narcov était encore engagé à l'Institut d'histoire de Chişinău, ${ }^{40}$ mais il ne publia plus rien sur l'appartenance de la Moldavie à la Galicie-Volhynie. Celui qui depuis la fin des années 1950 héritera de ce sujet est Nikolaj Moxov. Ce dernier, même dans les années 1970, continuera à soutenir que la Moldavie fit partie de la Galicie-Volhynie. ${ }^{41}$ Mais il le fera d'une manière assez étrange. D'une part, tout comme ses prédécesseurs, $\mathrm{il}^{42}$ invoqua le Dit de l'Ost d'Igor pour convaincre ses lecteurs qu'aux $\mathrm{XII}^{\mathrm{e}}$-XIII ${ }^{\mathrm{e}}$ siècles les princes galiciens-volhyniens exercèrent leur pouvoir sur le territoire de la Moldavie historique. D'autre part, $\mathrm{il}^{43}$ nota quà la même époque sur ce même territoire il existait plusieurs formations politiques qu'il appela «royaumes ». Selon Moxov, ${ }^{44}$ le plus important de ces royaumes serrait celui d'Ivan Berladnik, qui avait sa capitale à Berlad, localité qu' il identifiait avec la ville de Bârlad, située dans la partie du sud de la Moldavie roumaine. Tout comme Fedorov, Moxov ${ }^{45}$ parla de la présence en Moldavie des Vygontsy galiciens.

Nikolaj Moxov, il faut le préciser, a été l'un des plus importants représentants de l'historiographie soviétique moldave. Dans les années 1950-1970, il a été chargé du traitement des sujets de premier plan dans le système idéologique de la RSSM, soit l'ethnogenèse des Moldaves, la genèse de leur État et l'histoire de leur amitié avec les Russes et les Ukrainiens. ${ }^{46}$ C'est pourquoi la plupart de ses ouvrages avaient plutôt l'air d'un matériel de propagande que du résultat d'une recherche originale. Cela ne veut pas dire que l'idée de l'existence dans la région de la Moldavie d'un royaume berladien était une pure fiction. Dans le contexte de divers événements déroulés dans les années 1114-1162, les chroniques mentionnent un individu appelé Ivan Berladnik ainsi qu'une peuplade ou plutôt

${ }^{40}$ Protokoly Učenogo soveta Instituta za 1958 god. Moldavskij filial AN SSSR, Institut istorii, fond 18, opis' 1, nomer 4. Arhiva Academiei din Republica Moldova.

${ }^{41}$ Il faut toutefois préciser que ni Mohov ni d'autres historiens soviétiques ne parleront plus du « riche et précieux héritage » laissé par la Galicie-Volhynie dans la culture moldave ou de son importance pour l'apparition de l'État médiéval moldave.

${ }^{42}$ N.A. Mohov, Formirovanija moldavskogo naroda i obrazovanie Moldavskogo gosudarstva (Kišinev: Kartja moldoveniaskè, 1959), 23; N.A. Mohov, Očerki istorii moldavsko-russko-ukrainskix svjazei (s drevneišix vremen do načala XIX veka) (Kišinev, 1961), 16.

${ }^{43}$ Mohov, Formirovanija moldavskogo naroda, 22-28; Mohov, Očerki istorii moldavsko-russkoukrainskix svjazei, 17-19.

${ }^{44}$ Mohov, Formirovanija moldavskogo naroda, 24-27.

${ }^{45}$ Ibidem, 23-24.

${ }^{46}$ Ibidem; Mohov, Očerki istorii moldavsko-russko-ukrainskix svjazei; Mohov, Formirovanija moldavskogo naroda i obrazovanie Moldavskogo gosudarstva (Kišinev: Kartja moldoveniaskè, 1969); N.A. Mohov, Očerki istorii formirovanija moldavskogo naroda (Kišinev: Kartja moldoveniaskè, 1978). 
un groupe armé appelé Berladniki. ${ }^{47}$ Ces chroniques ne donnent pas de détails sur la position géographique du Berlad, mais plusieurs historiens russes ${ }^{48}$ ont remarqué, beaucoup avant Moxov, qu'une partie des activités militaires d'Ivan Berladnik se sont déroulées dans la région du Danube inférieur et vu l'existence dans le sud de la Moldavie roumaine d'une localité et d'une rivière homonymes, l'ont localisé dans cette région précise.

Quoi qu'il en soit, la présence sur le territoire de la future principauté moldave du royaume berladien et des «Vygontsy galiciens » aurait dû conduire Moxov à mettre en doute l'appartenance de ce territoire ou du moins d'une partie de celuici à la Galicie-Volhynie. Cela n’a jamais été le cas. ${ }^{49}$ Par contre, depuis le milieu des années 1960, Moxov $^{50}$ averti que sur le territoire de la Moldavie le pouvoir de la Galicie-Volhynie s'est manifesté d'une manière « instable » ou que le territoire de la Moldavie fit partie de la Galicie-Volhynie « de temps en temps ».

Nous avons noté que l'historiographie officielle ukrainienne soutenait aussi que la Moldavie historique fit partie de la Galicie-Volhynie. Comme représentant de première ligne de l'historiographie soviétique moldave, Moxov ne pouvait pas se permettre de contredire ouvertement l'historiographie officielle ukrainienne. Sans doute, à ses yeux cela pouvait être une gaffe idéologique très grave, d'autant plus que les archives moldaves révèlent Moxov comme un gardien attentif de la « correctitude » idéologique. Dans le contexte d'une discussion sur le manuscrit d'un chapitre de la variante soviétique de l'histoire de la Roumanie, rédigé par un historien moscovite, Moxov trouvait que les opinions de celui-ci sur l'histoire de la Transylvanie - province qui historiquement constituait la pomme de discorde entre les historiographies roumaine et hongroise - étaient influencées

47 Tel'nov, Stepanov, Russev, Roman Rabinovič, I... razošlis' slavjane po zemle, 135-139.

${ }^{48}$ S.M. Seredonin, Istoričeskaja geografija (Petrograd: Tipografija Glavnogo upravlenija udelov, 1916), 185; Nasonov, «Russkaja zemlja » i obrazovanie territorii drevnerusskogo gosudarstva, 140; M.I. Tixomirov, Drevnerusskie goroda (Moskva: Gosudarstvennoe izdatel'stvo političeskoj literatury, 1956), 209.

${ }^{49}$ Toutefois, pour atténuer cet illogisme Mohov va employer de petits artifices. Par exemple, il nota que parfois (il ne précise pas à quel moment et quels sont ses arguments), certains de ses royaumes (ils ne précisent pas lesquelles) se trouvent en dehors de la Galicie-Volhynie. Il va aussi suggérer qu' Ivan Berladnik, le supposé chef du royaume berladien, se considérait lui même en tant que vassal du knyaz galicien-volhynien. Dans le cas de «Vygontsy galiciens », selon Mohov, en fait, ils ne seraient pas réfugiés ou bannis en dehors de la Galicie-Volhynie, mais dans «les régions peu peuplées » de cet État. Cf. Mohov, Formirovanija moldavskogo naroda, 23, 25.

${ }^{50}$ N.A. Mohov, «Zaselenie kraja Volohami. Formirovanie moldavskogo naroda », Istorija Moldavskoi SSR (ot drevnejšix vremen do Velikoj oktjabr'skoj socialističeskoj revoljucii), édité par A.V Čerepnin, tom I, (Kišinev: Kartja moldoveneaskè, 1965), 80; Mohov, Formirovanija moldavskogo naroda i obrazovanie Moldavskogo gosudarstva, 43; Mohov, Očerki istorii formirovanija moldavskogo naroda, 48. 
par l'historiographie hongroise, ce qui selon lui, n'était pas admissible, car cette province appartenait depuis longtemps à la Roumanie et c'est donc le point de vue roumain qui aurait dû prévaloir. ${ }^{51}$ Les archives roumaines, à leur tour, dévoilent l'intervention de Moxov auprès d'Ion Popescu-Puțuri, un important idéologue du Parti communiste roumain, pour tempérer l'ardeur antirusse ou antisoviétique d'un historien roumain. ${ }^{52}$

\section{La Galicie-Volhynie et le territoire de la Moldavie selon la dernière synthèse soviétique d'histoire de RSSM}

Après la mort de Moxov, survenue en 1983, l'opinion sur cette question changera. Dans la dernière synthèse soviétique d'histoire de la RSSM parue en $1987,{ }^{53}$ ses auteurs se limitèrent à noter que le territoire de Moldavie a été seulement dans la sphère d'influence politique de la Galicie-Volhynie. Elle n'aurait pas constitué une partie effective de ce royaume. ${ }^{54}$ À part les ouvrages de Nasonov et Timoščuk, il n'est pas exclu quel'opinion de l'historiographie moldave ait été marquée quelque part par l'étude d'un autre ukrainien, l'historien Nikolaj Kotljar. Publiée deux ans avant la synthèse d'histoire de Moldavie, l'étude de Kotljar ${ }^{55}$ approfondit la voie tracée par Nasonov et Timoščuk en constituant l'analyse la plus étendue et, semble-t-il, la plus sceptique quant à une domination galicienne-volhynienne sur le territoire moldave qui soit parue à l'époque soviétique.

${ }^{51}$ Protokoly zasedanij Učenogo soveta Instituta za 1965 god, fond 18, opis’ 1, nomer 62. Akademija nauk MSSR, Institut istorii. Arhiva Academiei din Republica Moldova.

${ }^{52}$ Ioan Opriș, Istoricii și securitatea. Vol. II (București: Editura Enciclopedică, 2006), 349.

${ }^{53}$ V.L. Janin, éd. Istorija Moldavskoj SSR, pervobytnoob̌̌činnyj stroj. Perekhod k klassovomu obščestvu. Formirovanie feodal'nyx otnošenij. Obrazovanie Moldavskogo gosudarstva, tom I, (Kišinev: Kartja moldoveneaskè, 1987), 255, 317.

${ }^{54}$ Il faut remarquer aussi un certain changement d'accent, quoiqu'assez incohérent, dans l'historiographie officielle ukrainienne. Dans le premier volume d'une synthèse d'histoire de l'Ukraine paru au début des années 1980, ses auteurs ont parlé d'une «soumission politique et économique » de la région de Moldavie et non pas d'une intégration effective. Cf. I.I. Artemenko, éd. Istorija Ukrainskoj SSR: pervobytnoobščinnyj stroj i zaroždenie klassovogo obščestva. Kievskaja Rus' (do vtoroj poloviny XIII v.), Tom I, (Kiev: Naukova dumka, 1981), 404, 415. Toutefois, dans le deuxième volume, les historiens ukrainiens ont tenu à noter que la Bucovine fit partie de la Galicie-Volhynie et qu'à l'époque de son plus grand épanouissement, ses frontières ont touché le Danube, donc il aurait englobé le territoire entier de la Moldavie historique. En plus, selon les mêmes historiens, «plus tard » - ils ne précisent pas quand exactement - le territoire de Galicie-Volhynie s'amoindrit, pourtant toute la moitié du nord de Moldavie historique resta entre ses frontières. Cf. I.S. Slabeev, éd. Istorija Ukrainskoj SSR. Razvitie feodalizma. Narastanie antifeodal'noj i osvoboditel'noj bor'by (vtoraya polovina XIII - pervaya polovina XVII v.) (Kiev: Naukova dumka, 1982), 65, 326-327.

${ }^{55}$ N.F. Kotljar, Formirovanie territorii i vozniknovenie gorodov Galicko-Volynskoj Rusi, IX-XIII vv. (Kiev: Naukova dumka, 1985), 98-117. 


\section{... et après ?}

Au début des années 1990, la question de l'appartenance de la Moldavie à la Galicie-Volhynie bien que resta un sujet tout à fait marginal prendra une nouvelle dimension. C'est la période quand la société moldave est déchirée entre les discours pro-russe et pro-roumain. Le champ historiographique moldave n'échappera pas à cette réalité. C'est ainsi que certains de ses représentants ${ }^{56}$ estimeront que leurs recherches prouvent qu'au moins l'extrémité nord de la Moldavie fit partie de la Galicie-Volhynie tandis que d'autres ${ }^{57}$ vont affirmer que tous les arguments d'un tel état de choses sont complètement frêles.

\section{Un sujet historiographique et ses dimensions idéologiques : résumé}

Le but de cette étude est de faire ressortir les dimensions idéologiques du discours historiographique soviétique moldave porté sur la question de l'appartenance du territoire de la Moldavie au royaume médiéval de GalicieVolhynie. Nous avons noté que ce discours a été grandement marqué par la réanimation stalinienne de l'idéologie pan-russe et pan-slaviste, par la dispute soviéto-roumaine concernant la Bessarabie, ainsi que par la campagne d'inoculation à la population de cette province et de la RASSM du sentiment d'appartenance au monde slave de l'Est et donc à l'URSS.

L'accent de l'usage idéologique de la question de l'appartenance du territoire de la Moldavie à la Galicie-Volhynie tombe sur la période comprise entre la fin des années 1930 et le début des années 1950, quand les discours pan-russe et pan-slaviste se trouvent à leur apogée. À l'époque, à part avoir soutenu que le territoire de la Moldavie a appartenu jadis à la Galicie-Volhynie, on estimait que l'État médiéval moldave devait en partie son existence à ce royaume. Nous avons pourtant signalé aussi le cas d'un historien russe qui à cette même époque a manifesté son scepticisme quant à l'appartenance du territoire de Moldavie à la Galicie-Volhynie. Nous avons expliqué ce cas par le fait que le contrôle idéologique de l'État soviétique sur son historiographie n’a jamais été total, en permettant ainsi la parution des publications potentiellement indésirables.

Nous avons aussi signalé que depuis la fin des années 1950, un archéologue de Moscou, auteur de la première génération d'archéologues médiévistes moldaves, a pu profiter d'un contexte idéologique plus permissif pour suggérer que la Galicie-Volhynie aurait exercé uniquement une certaine influence politique et seulement sur l'extrémité nord de Moldavie. Plus tard, influencé par les études d'un archéologue ukrainien, il va rejeter ouvertement l'idée de

${ }^{56}$ A.V. Majorov, Galicko-Volynskaja Rus'. Očerki social'no-političeskix otnošenij v domongol'skij period. Knjaz', bojare i gorodskaja obščina (Sankt-Peterburg: Universitetskaja kniga, 2001), 230.

${ }^{57}$ Pavel Parasca, Gheorghe Postică, Préface au Relațiile românilor cu slavii de răsărit până la 1812, par Alexandru I. Gonța, 3-8, (Chişinău: Universitas, 1993), 7. 
l'appartenance du territoire de RSSM à ce royaume. Sa position sera partagée par tous ses disciples, mais pas par toute l'historiographie moldave. L'un des plus importants représentants de l'historiographie soviétique officielle de RSSM, qui manifesta une vigilance idéologique accrue, va continuer avec certaines nuances à soutenir que la Moldavie a fait partie de la Galicie-Volhynie. Son but était de ne pas entrer en contradiction avec l'historiographie officielle ukrainienne qui propageait la même opinion.

L'historiographie officielle de RSSM va abandonner cette idée en 1987 avec la parution de la dernière synthèse d'histoire de RSSM. Au début des années 1990, la problématique de la frontière du sud de la Galicie-Volhynie, prendra une nouvelle signification. Son traitement sera influencé par les discours prorusse et pro-roumain qui galvanisaient la société moldave de l'époque. 